\title{
NDM Integrated Organizational Structure and the Growth of Organizations
}

\author{
Markus Vanharanta and Mark Stevenson \\ Lancaster University Management School \\ m.vanharanta/m.stevenson@1ancaster.ac.uk,
}

\begin{abstract}
Motivation - To investigate how reliance on NDM-type coordinative practices facilitates and hinders the growth and survival of organizations. Research approach - Four year longitudinal case study design was used, combining action research and non-participant observations. Research limitations - This is ongoing research. Future research will explore the findings of this study in other companies. Originality / Value - The survival and growth of NDM integrated organizations is related to how material artefacts, such as computers, are simultaneously used to: (1) enhance pre-existing NDM-type coordinative decision-making; and, (2) facilitate the gradual transformation towards a differentiated organizational structure. Take away message - We observed 6 stages in this transformation process, enabling and constraining the adoption of computer applications.
\end{abstract}

\section{Keywords}

Naturalistic Decision Making (NDM); NDM Integrated Organizations; Coordination; Enterprise Resource Planning (ERP) systems

\section{INTRODUCTION}

Over the past 20 years, NDM-related cognitive research has made significant contributions to explaining how proficient decision-makers handle dynamic and changing real life contexts (e.g. Klein et al. 1993; Klein 1999; Lipshitz et al. 2001; Salas and Klein 2001; Zsambok and Klein 1997). Increasingly, however, this research tradition has aimed at going beyond the study of individuals and small groups, to also begin to address the relationship between organizational contexts and NDM-type decision-making (e.g. Gore et al. 2006; Lipshitz et al. 2006; Roth et al. 2006; Shattuck and Miller 2006). In addition, much of the early NDM research has been conducted in command and control type environments, such as the military, differing substantially from the organizational context of commercial firms, which is the focus of this paper.

In this paper, we aim to contribute to the NDM-related research literature by investigating the use of technology in NDM type coordinative functions (e.g. Johansson and Hollnagel 2007; Nyssen 2007; Ritter et al. 2007). More specifically, in this paper we investigate how a firm's reliance on NDM-type coordinative practices and related managerial competencies both facilitate and hinder organizational growth and survival at different stages of a firm's development. In addition, we argue that by facilitating NDM-type decision-making, computer artefacts can simultaneously have an important role as enablers of organizational growth, by functioning as the "glue" that enables wider collaboration and social ordering to take place. Yet, the need for computer based facilitation substantially differs in different stages of organizational growth, and in different organizational context. Thus, it is important to recognize the specific growth stages and contextual needs of firms. If however an organization fails to facilitate key NDM type coordinative processes with material artefacts, this in itself can become an obstacle for the growth and survival of organizations. In this paper we are referring to coordination as the management of "dependencies between activities" (Molone and Crowston 1994: 90), but also including the management of dependencies between events, things, objects and their relations, structures, and people.

Drawing on evidence taken from the four-year study of a small engineering firm, we initially identify a stereotypical organizational structure, where most operating activities were coordinated by key manager using NDM-type flexible decision-making. We call this basic organizational structure an NDM Integrated (NI) organizational structure. In a pure NI organization, all of the key activities are coordinated in the mind of just one person, which is manifested to different degrees in small and medium size organizations. 
Based on our observed practices, NI organizations can be highly responsive allowing for flexible ad-hoc alignment between organizational functions in response to environmental challenges. In a NI organization, a key managerial skill is thus to have an intuitive feel for the organization as a whole, which concerns all key functional activities, external relations, and how these activities link together. NI organizational structure thus allows for system-wide strategic handling of ad-hoc problems and opportunities, which can be a competitive advantage against larger, less nimble, enterprises with more fragmented and differentiated organizational structures. For example, in the past the output flexibility of small firms has been identified as a source competitive advantage (Fiegenbaum and Karnani 1991; Stigler 1939). However, the source of this competitive advantage has not been explicitly linked to NDM enabled coordinative mechanisms. In addition, a NI organizational structure can be attractive to small firms as it typically does not require extensive investment, relying primarily on the experience and managerial proficiency of the central coordinating manager. However, there are clearly limitations to how many operational functions one manager can effectively coordinate as an organization's size and complexity increases. Eventually, organizational growth requires more complex differentiated organizational structures (Lawrence and Lorsch 1967).

Using case study evidence, this paper examines causal powers at play when an organization reaches the coordinative limits of one central manager. While this question has previously been addressed through the concept of "residence" and "brittleness" (Hollnagel and Woods 2006), here, we describe a more a gradual developed of organizational "resilience" and "brittleness" over several years, where the use of computers increasingly complement and supplement NDM-type coordinative practices. We also explore how the gradual delegation of activities to computer artefacts can facilitate the formation of a more differentiated organizational structure, ultimately transforming the role of NDM-type decision-making. These observations are theoretically supported by the Actor-Network-Theory (ANT), which has studied how material artefacts, such as computers, act as "glue" in the formation of social ordering (Callon 1986; Latour 1987). ANT research originates from comparisons between human and baboon societies, where it was recognized that social ordering in baboon societies lacks extra-somatic resources (Latour 2007). Thus social order in a baboon society requires the constant physical presence of head-baboons. In comparison, in human social ordering, strategies are delegated to networks of extra-somatic resources, which have durability beyond our spoken words and the immediacy of physical acts.

"And that network [of material artefacts] includes buildings, computers, telephones, data, accounting software, and all the rest... Where as... the top baboon has no such extra-somatic resources. Snarling, chest beating, and physical violence - these are his weapons of first, but also of last resort" (Law 2002: 34)

To draw an analogy with baboon societies, a NI structure requires the continued coordinative presence of a central manager. Based on this, we argue that the growth of a NI organization has a distinctive "baboon-tipping point", beyond which the complexity, speed, and magnitude of coordinative endeavour requires the delegation of strategies to material artefacts, such as computers.

Overall, this paper seeks to build theory which explains under what circumstances it is beneficial and/or possible for small firms to operate using a NI structure, and how the underlying NDM-type coordinative practices can be transformed without major disruptions to a firm's operations. The remainder of the paper is organised as follows. Section 2 provides a brief overview of the mixed research methods employed in this study. Section 3 then provides presents the case study company and the stages of its growth that we have observed. Finally, the paper concludes in Section 4.

\section{RESEARCH METHOD}

This is an inter-disciplinary case, with mixed research methods, bringing together the findings from two separate research projects/teams conducted in the same small UK-based engineering company, hereafter referred to as Company M. The research has been conducted longitudinally between 2003 and 2008; projects overlapped but did not influence each other significantly. By combining resources, this longitudinal approach is now able to study and understand how the organization has changed, developed and grown over time. A range of data collection methods were used during the studies, including semi-structured interviews with notes and/or audio recording, observations, historical secondary data, quantitative data (e.g., on delivery performance) and journal/diary keeping.

One of the projects was an action research-oriented project, involving participant-observation, where the researcher had a hands-on role in developing software based on a production planning and control method known as Workload Control, intended for use in the company. The participant observer conducted action research in the company over an eighteen month period between 2003 and 2005 and has also supervised postgraduate student projects in the company in 2008. The other research project investigated the firm's customer relationship management practices, relying mainly on non-participant observations, where the owner-manager was 'work shadowed' during his daily activities for a whole 
week in 2004. The non-participant observer conducted a follow-up interview in 2006; a second follow-up interview, at which researchers from both research teams were present, was conducted with the owner-manager in 2008.

\section{CASE STUDY EVIDENCE}

Company $\mathrm{M}$ is a small precision engineering company located in the UK. The company currently employs 55 people and has an annual turnover in excess of $£ 3 \mathrm{~m}$. The company produces bespoke subcontracted items, in varying quantities, for larger-UK based manufacturers. Typical customers can be found in the aerospace, automotive, rail and defence industries, with a previous diversification into manufacturing parts for Formula One and Le Mans racing teams.

Company $\mathrm{M}$ is a family firm with a turbulent history. A company was originally formed in 1955 by the father of the current owner-manager. This first company grew over time and employed 55 people at its most successful; however, in 1993 it became bankrupt. A new company was formed by the present owner-manager immediately after with 16 staff, rising to 52; however, in 2001, the company again became bankrupt. The current manifestation of Company $\mathrm{M}$ started in 2001 with a staff of 17 at the same site as the previous companies, with many of the same employees and customers, with much of the same management personnel and structure, and manufacturing the same type of products.

In evaluating the past, the current owner-manager realised that the overreliance on a key coordinative manager had been a major cause of the business failures. Both of the failed companies had operated primarily using the NI structure, eventually reaching the "baboon-tipping point" with staff of around 50-55 employees. Thus, in founding the family's third business venture in 2001, the owner-manager was convinced that he could only grow the new firm beyond 50 employees if he delegated some of his coordinative strategies to formalised planning procedures and coordinating mechanisms, such as an Enterprise Resource Planning (ERP) computer system. Therefore, in 2002, the owner-manager decided to commission the development of a custom-built ERP software program, known as CERP, to reduce the organization's dependence purely on NDM-type coordinative decision-making. The main reason why the ownermanager wished to build his own ERP system, rather than buy a commercially available off-the-shelf solution, was that he wanted to maintain control over how it would operate and work alongside his more ad-hoc NI processes, in which NDM-type decision-making played a key role.

Our longitudinal case study observations focus on this third family-owned corporation throughout the development and implementation of CERP. The following discussion is organised around six stages that, step-by-step, transform the modus operandi of the organization.

\section{Stage 1: Operating with a NI structure}

At the time of our work-shadowing of the owner-manager in 2004, the firm employed 30 people, and its operating model was largely based on a NI structure, where the owner-manager was personally coordinating most of the firm's activities. The observed social ordering at Company $\mathrm{M}$ was thus reliant on the constant presence of the owner-manager, who worked at the company for 7 long days a week without holidays. Thus, here an analogy can be made to how a head-baboon's presence is continuously required if order is to be maintained in a baboon society. For example, the CEO was personally responsible for handling all of the key customer and supplier relationships, while at the same time having a hands-on role in coordinating the firm's in-house and outsourced manufacturing activities. Being the only person in the firm who had an overall picture of the entire organization, the owner-manager was constantly fire-fighting, i.e., being called on to make on-the-spot decisions in different operational areas of the firm. The owner-manager was operating in a highly dynamic environment, under constant time-pressure, making decisions with high stakes, potentially affecting the survival of the organization. Overall, the owner-manager's coordinative decision-making style had most of the commonly accepted characteristics of NDM (Orasanu and Connolly 1995).

At this stage, the company made minimal use of information systems and its own CERP was still at an early stage of its development. For example, Company M lacked a formalised approach to production planning and control. Instead, the low production volume enabled a manual scheduling approach to be used to control the shop floor. The approach to planning production was to use a list of machines on a whiteboard and to simply write the job reference numbers of urgent jobs over the next few days under each relevant machine; most of this information was held in the ownermanager's head. The whiteboard was reviewed every three to five days, and jobs wiped off the board when completed, with other urgent jobs taking their place. As a result, the owner-manager (and shop floor supervisor) spent much of their time continuously rushing urgent jobs through the shop floor.

It was at this point that, as part of our action research, we attempted to implement a formalized computer-based decision support system, based on a production planning and control concept known as Workload Control (see Stevenson 2006). However, the attempted software implementation failed and the project was suspended indefinitely. In hindsight there are many reasons for this implementation failure. Most importantly, at this stage of the firm's growth, the ad-hoc flexibility facilitated by the NI structure and related NDM-type decision-making had several advantages over more formalized computer based systems. For instance, as long as the owner-manager could maintain an overall big-picture understanding of the relative importance of different operational processes, his experience allowed him to dynamically 
shift resource emphasis between different operational functions and business objectives. This was particularly important as Company $\mathrm{M}$ had very limited resources at its disposal, requiring constant value-judgments to be made between different competing priorities. Instead of wanting to use our computer generated job due dates for customer deliveries, the owner-manager felt that he could better take the firm's situation into consideration using his own situational judgments. For example, when dealing with a potentially important customer, the owner-manager was often eager to please them and to tell them "what we think they want to hear". The firm's ability to deliver promised goods on time was a secondary problem, which the owner-manager tried to manage later on with various sub-contractor arrangements, and by sometimes delaying the jobs of less important customers. When these practices angered some of the less significant customers, the owner-manager tended to temporarily improve the level of service given to these customers. Overall, resource allocations where dynamically altered based on situational opportunities, which among other considerations included production schedules, customer sentiment, order book size, technological know-how, material availability, and financial constraints.

The owner-manager's belief in his ability to, largely intuitively, manage both the manufacturing process and customer relationship aspects of the business were summarized in his comment to us that: "I don't need a system that is going to tell me what I already know (i.e., that deliveries are going to be late) ..." Ultimately, at this growth stage, the company was not in a state of readiness for an information system; the owner-manager was still (just about) able to cope using a largely intuitive NDM-type coordinative approach. In addition, he was concerned that the system would take away some of his decision-making power and take up too much of his time, which could otherwise be spent on other activities which, at that time, he perceived to be more important.

\section{Stage 2: Approaching the "baboon-tipping point"}

By the time of our 2004 observations, the owner-manager was already under considerable time-pressure to handle all relevant aspects of Company M's operations. After 2004, as the firm grew, these pressures began to increasingly hinder the firm's operational efficiency. For example, by the time of our 2006 follow up interviews, the owner-manager had stopped sending weekly delivery promises to key customers, despite their perceived importance. He simply did not have the time required to generate such reports manually. At the same time, as the firm's order book grew to over 300 jobs, it had become increasingly difficult for the owner-manager to keep track of all jobs, their delivery deadlines, and other related considerations. Overall, it was clear to us as observers, and also to the owner-manager, that Company $\mathrm{M}$ could not grow much beyond this point without fundamental changes being made to its operating practices and related structures.

\section{Stage 3: Stretching the "baboon-tipping point" with computers}

In 2007, the specified functionality of CERP was $80 \%$ complete and it had been implemented in the front-end office of the company. At this point in time the CERP system was used for human resource-related issues, and as a database of customer addresses and sales contacts. Thus, instead of the owner-manager trying to remember employee details, up-todate absenteeism issues, customer names, etc., this information began to be stored in the CERP system. In 2008, the company's order pool had grown to over 500 jobs and the CERP functionality was extended from the front-end to the back-end of the company, e.g., to include information about jobs currently on the shop floor (known as a shop floor data collection system), such as routings, quantity complete, current operation, etc. This had an even more significant impact, making NDM-type coordinative decision-making easier.

\section{Stage 4: Going beyond the "baboon-tipping point" through information sharing}

In addition to helping the owner-manager's NDM-type coordinative processes, the CERP system allowed key information to be shared within the organization. While in the past, the owner-manager had kept much of his situational awareness largely to himself, this key information now became accessible to the entire management team. Thus, instead of asking the owner-manager, other staff could now find out many of the answers they required from the CERP system. Thus, this step further reduced the pressures on the owner-manager, allowing him to increase his focus on strategic aspects of running the business.

\section{Stage 5: Gradual transition to a differentiated organizational structure}

Company $\mathrm{M}$ was able to increase its division of labour as more and more information began to become accessible to the management team. In this new managerial structure, the CERP system thus acted as "glue" linking the different aspects of management together. In addition, as the functionality of CERP was extended, the owner-manager was able to standardise processes across the company more and more. This means that the organization's overall reliance on the owner-manager's NDM-type coordinative activity was reduced. However, the coordinative skills remained important, in order to maintain responsiveness to ad-hoc events. Thus, despite the standardization, the owner-manager found it necessary to override the system on a daily basis. As measures of operational efficiency, these changes resulted in a notable reduction in late deliveries. In addition, the firm's job pool had, by 2008, grown to approximately 600 jobs, which was far beyond what the past family enterprises had handled at their peak before the bankruptcies. At our last interview, the owner-manager reflected that: "when we had 250-300 jobs, I knew all the work in the factory but I knew then that if it got to $350-400$ jobs, I'd be struggling ... we now have 598". 


\section{Stage 6: Decision support for NDM}

As the company continues to grow, the scope of CERP is being extended and further modules are being implemented. For example, while our implementation of production planning and control software failed in 2004, at this stage of organizational growth, the owner-manager is now interested in building this functionality into CERP. If functionality such as Workload Control is added to the system, it would take CERP beyond being just a database of information, to a system that genuinely supports and interacts on decision-making activities and suggests solutions to the company's problems. Even at this advanced stage, however, the owner-manager is still keen to maintain some level of NDMrelated flexibility, in particular to maintain an organizational ability to over-ride the decisions suggested by computer systems.

Interestingly, a very similar sequence of events is taking place at Company $\mathrm{R}$, which Company $\mathrm{M}$ has recently purchased. This provides a comparative case, supporting the arguments put forward in this paper. Company $\mathrm{R}$ operates in the same industry as Company M, currently employing 15 employees, and is located near to Company M. Yet, even though the CERP software is owned and developed by Company M, the owner-manager has decided not to implement CERP at Company R. Instead, it was his judgment that a NI-type organizational structure, and the flexibility of NDMtype coordinative practices, are better suited to the size of Company R's operations. This, however, is likely to change if Company R grows in size and approaches the "baboon-tipping point".

\section{CONCLUSIONS}

Managing organizational growth presents a significant challenge to the survival of an organization. Drawing on evidence from the four-year longitudinal study of a small engineering firm has allowed the research team to observe a company at various points in its growth. We have investigated how reliance on NDM-type coordinative practices can both facilitate and hinder the growth and survival of a small organization, at different stages of its development. In addition, we observed how the growth and survival of a firm can be facilitated by the step-by-step delegation of activities to material artefacts, such as computer information systems. We identified 6 stages in this process, which can be used to judge the appropriate level for facilitating NDM-type coordinative decision-making with computer artefacts.

In accordance with Actor-Network-Theory, the computer artefacts assisting NDM-type decision-making acted as the "glue" in enabling wider collaboration and social ordering to take place, facilitating organizational growth. Social ordering thus needs to be seen as a significant consideration in evaluating how computer artefacts improve and hinder NDM-type coordinative decision-making. In addition, to avoid the zoological elision, it is significant to recognize how "baboon-like" qualities in NDM decision-making, and related organizational inertia, can resist attempts to delegate social ordering strategies to more durable material elements. Overall, the coordinative transformation beyond a NDM integrated structure is an existential challenge for small firms as the volume of their operating activities approaches what we have identified as the "baboon tipping point". It is thus significant for small firms to recognize when and for how long it is beneficial and/or possible to operate with a NDM Integrated organizational structure, and how these NDM-related practices can be complemented with computer artefacts. Future research will explore the findings of this study in other companies and continue to observe and reflect on the growth of Company M and CERP.

\section{REFERENCES}

Callon, Michel (1986), 'Some Elements of a Sociology of Translation: Domestication of the Scallops and the Fishermen of St Brieuc Bay', in John Law (ed.), Power, Action and Belief: A New Sociology of Knowledge (London: Routledge and Kegan Paul).

Fiegenbaum, Avi and Karnani, Aneel (1991), 'Output Flexibility - A Competitive Advantage for Small Firms', Strategic Management Journal, Vol. 12, No. 2, pp. 101-14.

Gore, Julie, et al. (2006), 'Naturalistic Decision Making and Organizations: Reviewing Pragmatic Science', Organisation Studies, Vol. 27, No. 7, pp. 925-42.

Hollnagel, Erik and Woods, David (2006), Resilience Engineering: Concepts and Precepts (Aldershot: Ashgate Publishing).

Johansson, Bjorn and Hollnagel, Erik (2007), 'Pre-Requisites for Large Scale Coordination', Cogn Tech Work, Vol. 9, pp. 5-13.

Klein, Gary (1999), Sources of power: How people make decisions (Cambridge, Massachusetts: The MIT Press).

Klein, Gary, et al. (eds.) (1993), Decision Making in Action: Models and Method (1995 edn., Norwood, New Jersey: Ablex Publishing Corporation ).

Latour, Bruno (1987), Science in Action: How to Follow Scientists and engineers through society (Cambridge: Harward University Press). 
Latour, Bruno (2007), Reassembling the Social: An Introduction to Actor-Network-Theory (Oxford: Oxford University Press).

Law, John [2002], 'Ordering and Obduracy', (Centre for Social Sciences, Lancaster University).

Lawrence, Paul R. and Lorsch, Jay W. (1967), 'Differentiation and Integration in Complex Organizations', Administrative Science Quarterly, Vol. 12, No. 1, pp. 1-47.

Lipshitz, Raanan, Klein, Gary, and Orasanu, Judith (2001), 'Focus Article: Taking Stock of Naturalistic Decision Making', Journal of Behavioral Decision Making, Vol. 14, pp. 331-52.

Lipshitz, Raanan, Klein, Gary, and Carroll, John S. (2006), 'Introduction to the Special Issue. Naturalistic Decision making and Organizational Decision Making: Exploring the Intersections', Organization Studies, Vol. 27, No. 7, pp. 917-23.

Molone, T. and Crowston, K. (1994), 'The Interdisciplinary Study of Coordination', ACM Cumputing Surveys, Vol. 26, No. 1, pp. 87119.

Nyssen, Anne-Sophie (2007), 'Coordination in Hospitals: Organized or Emergent Process?', Cogn Tech Work, Vol. 9, No. 149-154.

Orasanu, Judith and Connolly, Terry (1995), 'The Reinvention of Decision Making', in Gary Klein, et al. (eds.), Decision Making In Action: Models and Methods (New Jersey: Ablex Publishing Corporation).

Ritter, Jill, Lyons, Joseph, and Swindler, Stephanie (2007), 'Large-Scale Coordination: Developing a Framework to Evaluate Socio-Technical and Collaborative Issues', Cogn Tech Work, Vol. 9, pp. 33-38.

Roth, Emilie, Multer, Jordan, and Raslear, Thomas (2006), 'Shared Situation Awareness as a Contributor to High Reliability Performance in Railroad Operations', Organization Studies, Vol. 27, No. 7, pp. 967-87.

Salas, Eduardo and Klein, Garry (eds.) (2001), Linking Expertise and Naturalistic Decision Making (London: Lawrence Erlbaum Associates, Publishers).

Shattuck, Lawrence G. and Miller, Nita Lewis (2006), 'Extending Naturalistic Decision Making to Complex Organizations: A Dynamic Model of Situated Cognition', Organization Studies, Vol. 27, No. 7, pp. 989-1009.

Stigler, G. (1939), 'Production and Distribution in the Short Run', Journal of Political Economy, Vol. 47, No. 3, pp. 305-27.

Zsambok, Caroline E. and Klein, Gary (eds.) (1997), Naturalistic Decision Making (New Jersey: Lawrence Erlbaum Associates). 